\title{
Contribuições do diálogo entre o realismo crítico e o construcionismo social para os estudos organizacionais
}

\author{
Alex Fernando Borges

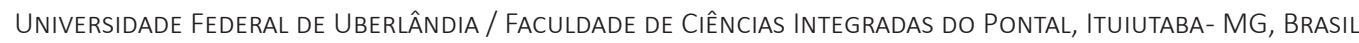 \\ MOZAR JosÉ DE BRITO \\ Universidade federal de LaVras / Programa de Pós-Graduação em Administração e Programa de Pós-GraduaçÃo em \\ AdMINISTRAÇÃo PÚBLICA, LAVRAS- MG, BRASIL \\ Valéria da Glória Pereira Brito \\ Universidade Federal de lavras / Programa de Pós-Graduação em Administração Pública, LaVras- MG, Brasil
}

Alessandro Gomes Enoque

Universidade Federal de Uberlândia / FAculdade de CIÊNCIAS INTEgRAdAS do PontaL, ITUIUTABA- MG, BRASIL

\begin{abstract}
Resumo
Neste artigo, tecemos algumas reflexões de natureza ontológica e epistemológica sobre a pesquisa em administração. Mais precisamente, procuramos apresentar os fundamentos de um possível diálogo entre o realismo crítico e o construcionismo social, constituindo um quadro de referência para o desenvolvimento de estudos organizacionais. Para tanto, retomamos, de forma breve e não exaustiva, as principais formulações e elaborações disponíveis sobre cada uma dessas concepções, de modo a situar suas especificidades e respectivos pressupostos ontológicos e epistemológicos centrais. De forma complementar, apontamos algumas contribuições dessa aproximação para os estudos organizacionais, ressaltando seu potencial filosófico para a construção de pesquisas de natureza multirreferencial. Esse diálogo pode contribuir para o desenvolvimento de estudos que incorporem os pressupostos ontológicos do realismo crítico e os fundamentos filosóficos da epistemologia construcionista social. Assim, verificamos a existência de pontos de convergência e complementaridade entre essas concepções, que no limite, podem servir de referência para a configuração de uma abordagem caracterizada por uma ontologia realista e por uma epistemologia construcionista que não nega a realidade e a sociedade como sendo, ao mesmo tempo, socialmente construída e real, em uma relação dialética entre agência e estrutura que supera dicotomias ainda presentes na teoria social e nos estudos organizacionais.
\end{abstract}

Palavras-chave: Ontologia. Epistemologia. Metodologia. Teoria das Organizações.

\section{The contributions of dialogue between critical realism and social constructionism to organizational studies}

\begin{abstract}
In this paper, we aim to present some reflections about the ontological and epistemological nature of Management research. More precisely, we expose the foundations of a possible dialogue between critical realism and social constructionism, constituting a reference framework for the development of organizational studies. In order to do so, a brief and non-exhausting discussion of these conceptions' main formulations and elaborations was made, positioning its particularities and its central ontological, epistemological, and methodological issues. In addition, some contributions of this approach to organizational studies were pointed out, emphasizing its philosophical potential for the definition of multi-referential researches. We observe that this dialogue can contribute to the development of organizational studies that incorporate the ontological assumptions of the critical realism and the philosophical foundations of the social constructionist epistemology. Thus, we conclude that the convergences and complementarities between these conceptions may, ultimately, contribute to the configuration of a approach, marked by a realist ontology and a constructionist epistemology that does not reject reality and society as being, at the same time, socially constructed and real, in a dialectical relation between agency and structure that overcomes dichotomies that are still present in both social theory and organizational studies.
\end{abstract}

Keywords: Ontology. Epistemology. Methodology. Organizational Theory.

\section{Aportes del diálogo entre el realismo crítico y el construccionismo social para los estudios de la organización Resumen}

En este artículo, presentamos algunas reflexiones ontológicas y epistemológicas de la investigación en administración. Más precisamente, tratamos de introducir los fundamentos de un posible diálogo entre el realismo crítico y el construccionismo social, proporcionando un marco para el desarrollo de los estudios de la organización. Con este fin presentamos, de forma breve y no exhaustiva, las principales formulaciones y elaboraciones disponibles en cada uno de estos conceptos con el fin de situar a sus particularidades y su núcleo ontológico y epistemológico. Como complemento, señalamos algunas contribuciones de este enfoque para los estudios de la organización, destacando su potencial filosófico para la construcción de investigaciones de naturaleza multirreferencial. Este diálogo puede contribuir al desarrollo de estudios que incorporen los fundamentos ontológicos del realismo crítico y los fundamentos filosóficos de la epistemología construccionista social. Por lo tanto, encontramos puntos de convergencia y complementariedad entre estas concepciones, que, al final, pueden servir de referencia para la creación de un enfoque que se caracteriza por una ontología realista y por una epistemología construccionista que no niega que la realidad y la sociedad son, al mismo tiempo, socialmente construida y real, en una relación dialéctica entre agencia y estructura que supera todavía dicotomías presentes en la teoría social y en los estudios de la organización.

Palabras clave: Ontología. Epistemología. Metodología. Teoría de la Organización. 


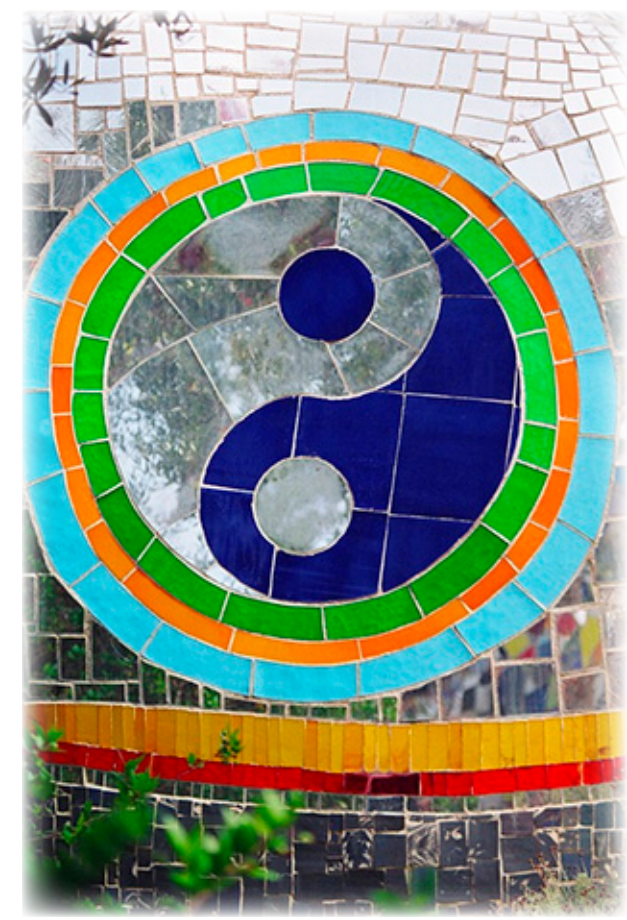

\section{INTRODUÇÃO}

Ao longo das últimas décadas, o debate sobre os pressupostos ontológicos e epistemológicos que orientam a produção do conhecimento em Administração e em estudos organizacionais tem alcançado maior relevância e destaque. No Brasil, essa discussão tem sido proposta por autores como Serva e Pinheiro (2009), Damke, Walter e Silva (2010), Barbosa, Santos, Matos et al. (2013), e Serva (2013). Os trabalhos mencionados expõem múltiplos enfoques de investigação, evidenciando diferentes posicionamentos adotados pelos pesquisadores brasileiros em relação aos pressupostos filosóficos e científicos da área.

Nesse cenário, podem ser observadas iniciativas para se compreender as diversas possibilidades de pensamentos referenciais e de posturas ontológicas e epistemológicas formuladas no âmbito da filosofia das ciências e da sociologia do conhecimento, e que foram apropriadas pelos pesquisadores do campo da administração e dos estudos organizacionais. Essa diversidade apresenta amplo escopo, englobando desde perspectivas fundamentadas no positivismo (SILVINO, 2007; BRANDÃO, 2011), passando pelo interpretativismo (VERGARA e CALDAS, 2005), pela abordagem crítica (FARIA, 2009), pelo pós-modernismo (SOUZA, 2012), pelo pragmatismo (BAERT, 2005; MENEGHETTI, 2007; HOLMWOOD, 2011), pela hermenêutica (PRASAD, 2002; ROBERGE, 2011), pela abordagem da complexidade (FRANCELIN, 2005; SERVA, DIAS e ALPERSTEDT, 2010), pelo construcionismo (GERGEN, 1985; SOUZA FILHO, 2007), pelo realismo crítico (HAMLIN, 2000; FLEETWOOD, 2005; HUNT, 2005; KEMP, 2005), dentre outras. Essa pluralidade, além de refletir a variedade de posicionamentos epistemológicos e ontológicos dos pesquisadores da área, também evidencia desafios associados ao processo de apreensão de diferentes fenômenos sociais e organizacionais.

Neste trabalho, abordamos a discussão filosófica em Administração e nos estudos organizacionais a partir das duas últimas concepções mencionadas acima: o construcionismo social e o realismo crítico. Essas abordagens, de acordo com Al-Amoudi e Willmott (2011), surgiram como amplos quadros de referência, agregando posturas ontológicas e epistemológicas cujos fundamentos induziram a produção de diferenciações em termos de afiliações teóricas e de alternativas de análise. Para os autores, esses quadros de referência filosófica foram tomados pelos pesquisadores como sendo inconciliáveis. Essa oposição

* Fonte da imagem: Disponível em <https://pixabay.com/pt/niki-de-saint-phalle-arte-artista-67685/> Acesso em 14 mar. 2016. 
e o debate dela decorrente foram responsáveis pela produção de críticas e controvérsias próprias da "guerra paradigmática", que resultou em uma espécie de incomensurabilidade ontológica e epistemológica (REED, 2005). Não obstante, esse conflito tem sido objeto de contestação. Recentemente, alguns autores têm produzido reflexões que propõem o diálogo construído a partir de convergências, complementaridades e aproximações entre esses modos de pensamento (ELDER-VASS, 2012). Em nosso artigo, reconhecemos a relevância dessa questão e realizamos uma sistematização reflexiva, que abriga diversas considerações acerca das possibilidades de diálogo entre realismo crítico e construcionismo social. Buscamos, também, apontar algumas contribuições desse diálogo para os estudos organizacionais, ressaltando suas colaborações para a construção de pesquisas orientadas por uma concepção ontológica realista e por uma postura epistemológica construcionista.

Antes de iniciarmos a exposição de nossos argumentos em prol do diálogo entre realismo crítico e construcionismo, torna-se necessário apontar alguns conceitos relevantes para nortear as discussões que serão aqui empreendidas. Entendemos a ontologia como um ramo da filosofia da ciência que procura compreender as diferentes concepções científicas sobre a natureza da realidade (LINCOLN, LYNHAM e GUBA, 2011; CRESWELL e CLARK, 2007). Para Fleetwood (2005), a nossa concepção de realidade pode influenciar o modo como podemos conhecê-la e como podemos investigá-la. Esse autor reconhece a estreita relação entre a ontologia e a epistemologia, entendida aqui como ramo da filosofia da ciência que tem por objeto de reflexão o saber científico, tecnológico e filosófico, com o intuito de explicar sobre seus diferentes condicionamentos (técnicos, históricos, sociais, por exemplo) e organizar e sistematizar suas relações, esclarecer seus vínculos e avaliar seus resultados e aplicações (FARIA, 2012). Para o autor, a epistemologia pode ser concebida como o estudo sistemático do conhecimento e estaria relacionada à ontologia na medida em que tenta explicar a natureza dos diferentes conhecimentos sobre a realidade e a forma como estes são produzidos, incluindo a concepção da relação entre o pesquisador e aquilo que ele pretende pesquisar.

O artigo está estruturado nas seguintes seções, além desta introdução: primeiro, apresentamos, de forma breve, os pressupostos do construcionismo social; segundo, apresentamos algumas considerações sobre os pressupostos do realismo crítico; terceiro, discutimos as possibilidades de compatibilidade, complementaridade e diálogo entre construcionismo e realismo crítico, de modo a apresentar a noção de construcionismo social-realista e/ou realismo crítico-construcionista. Por fim, nas considerações finais, identificamos algumas contribuições dessa abordagem para os estudos organizacionais e discutimos possibilidades de futuras pesquisas envolvendo essa relação.

\section{CONSTRUCIONISMO SOCIAL}

A origem do construcionismo social está atrelada aos questionamentos sobre as epistemologias universalistas de produção do conhecimento. Para Spink e Frezza (2004), essa abordagem abriga reflexões produzidas no âmbito de diferentes disciplinas, dentre as quais podemos citar: a) a filosofia do conhecimento, que questionava e continua questionando os fundamentos da lógica representacionista das ciências humanas e sociais; b) a sociologia do conhecimento, que passou a defender a desconstrução da retórica da verdade científica e tomar o conhecimento e a realidade como algo construído; c) a ciência política e a história, que procuravam gerar novos conhecimentos que visam maior conscientização e emancipação das coletividades marginalizadas. Spink e Frezza (2004) ainda apontam que os termos "construcionismo" e "construção social" têm sido empregados para, respectivamente, qualificar, teoricamente, a referida abordagem e explicar a ação coletiva em diferentes contextos sociais. Esse entendimento também foi compartilhado por Burr (1985) ao afirmar que o construcionismo emergiu a partir da problematização da visão hegemônica de ciência que preconizava a neutralidade e não reconhecia a relevância do contexto sócio-histórico para a produção do conhecimento.

Esse movimento de revisão dos postulados filosóficos do construcionismo social está presente no debate e nas práticas cotidianas de pesquisadores da área de Administração. Segundo Cunliffe (2008), essa abordagem, que se tornou popular nas décadas de 1970 e 1980, influenciou de maneira significativa as práticas de pesquisa que passaram a conceber as organizações - bem como o conhecimento sobre elas - como sendo socialmente construídas. O livro "A Construção Social da Realidade", de Berger e Luckmann (2005), publicado originalmente em 1966, foi determinante para a configuração acadêmica da abordagem construcionista. Para Spink e Frezza (2004), os postulados presentes na referida obra inovaram ao subverter uma ordem instituída pelos sociólogos do conhecimento, que abordavam as questões ontológicas e epistemológicas sob a ótica da história 
das ciências. Para as autoras, em "A Construção Social da Realidade", há um deslocamento desse modo de pensar, colocando em evidência o conhecimento do senso comum e as formas de sua produção e reprodução.

Berger e Luckmann (2005), ao discutirem o conhecimento como algo socialmente construído, conceberam que a sociedade é constituída simultaneamente por realidades objetivas e subjetivas, sendo que a sua construção seria produto dos processos de externalização, objetivação e internalização. De acordo com essa concepção, a sociedade passou a ser considerada como uma construção social, uma realidade objetivamente estabelecida por meio dos processos de institucionalização e tipificação cujos fundamentos podem ser aprendidos a partir de processos de socialização e reproduzidos por pessoas em suas práticas cotidianas. Se, por um lado, os autores reconhecem que as pessoas também são produtos de uma dada ordem social, ou seja, produtos de processos de socialização primária e secundária, por outro, eles pressupõem que o conhecimento e os significados produzidos por eles também seriam construções sociais. Esses fundamentos foram amplamente disseminados e compartilhados por pesquisadores de diversas áreas do conhecimento, que passaram a conceber a realidade social, as identidades e o conhecimento como construções marcadas por elementos culturais e linguísticos próprios de um dado contexto sócio-histórico (CUNLIFFE, 2008).

Gergen (1985), por seu turno, posiciona a origem do construcionismo social no âmbito da psicologia social enquanto um corpo de conhecimento emergente que possui repercussões de substancial relevância acadêmica. $\mathrm{O}$ autor aponta para a necessidade de se entender o construcionismo em contraposição a duas tradições intelectuais concorrentes: de um lado, os empiristas lógicos traçaram a fonte do conhecimento (como representação mental) em eventos do mundo real. De acordo com essa abordagem, o conhecimento deveria, idealmente, copiar os contornos do mundo. Essa perspectiva exógena tende a ver o conhecimento como uma garantia do natural e esse conhecimento espelha as atualidades do mundo real. Por outro lado, os adeptos da fenomenologia, tendem a assumir uma perspectiva endógena em relação às origens do conhecimento. Nesse caso, o conhecimento depende dos processos endêmicos do organismo social, de modo que os seres humanos abrigam tendências inerentes para pensar, categorizar ou processar informações, e são essas tendências (ao invés de características do mundo em si) que são importantes para a construção do conhecimento (GERGEN, 1985).

Para Gergen (1985), o construcionismo busca superar o dualismo tradicional entre sujeito e objeto (desafiando os próprios dualismos como base para uma teoria do conhecimento científico), desenvolvendo um novo quadro de análise fundamentado em uma teoria alternativa (não empirista) que ajuda a esclarecer os potenciais das ciências sociais e humanas. Essa abordagem confronta, então, a concepção ocidental tradicional de conhecimento objetivo, individualista e a-histórico. Na medida em que essa visão é questionada, chega-se à possibilidade de construção de uma alternativa teórico-científica baseada nos pressupostos do construcionismo social. Essa meta teoria procura remover o conhecimento de domínios positivistas e/ou necessariamente cognitivistas, e colocá-lo em termos das relações interpessoais. Consequentemente, as formulações científicas não seriam resultado de uma aplicação impessoal de regras metodológicas descontextualizadas, mas sim da responsabilidade de pessoas em trocas ativas comuns (GERGEN, 1985).

Os pesquisadores adeptos do construcionismo social procuram desvendar e explicar os processos pelos quais as pessoas descrevem, explicam e/ou dão conta do mundo em que elas vivem, incluindo a si próprias (SPINK e MENEGON, 2004). Sob essa perspectiva, os teóricos tentam articular formas comuns para compreender como as pessoas existem agora, como elas existiram em tempos históricos anteriores e como elas podem existir caso uma atenção criativa seja para elas direcionada (GERGEN, 1985; SPINK e MEDRADO, 2004). Na visão de Gergen (1985), aquilo que nós tomamos como experiência do mundo não dita por si só os termos pelos quais o mundo é compreendido e o que assumimos como conhecimento do mundo não é produto de dedução ou de formulação e teste de hipóteses gerais. Sendo assim, o construcionismo social toma como base uma dúvida radical sobre o mundo dado como certo e, de um modo especial, age como uma forma de crítica social. A adoção da abordagem construcionista social requer a suspensão da crença de que categorias ou conhecimentos comumente aceitos recebem sua garantia por meio de observação. Desse modo, esse quadro de referência convida o pesquisador a desafiar a base objetiva do conhecimento convencional, e esse critério objetivo para a identificação de "comportamentos", "eventos" ou "entidades" demonstra ser altamente circunscrito pela cultura, história ou contexto social (GERGEN, 1985).

Outro aspecto que merece destaque nessa discussão diz respeito à centralidade da linguagem e das práticas discursivas na produção do conhecimento e construção da realidade. Diversos autores apontaram para a existência de uma "virada" cultural e linguística na teoria social (VAARA, 2010; LECLERCQ-VANDELANNOITTE, 2011). Essa virada se caracterizou pela busca 
do sentido presente em diferentes produções discursivas (como textos, narrativas etc.) a partir de lentes analíticas que se diferenciam de abordagens estruturalistas dominantes no campo das ciências humanas e sociais. Sob essa perspectiva, o sentido não estaria no texto em si mesmo (como na análise de conteúdo), mas sim em uma ampla rede simbólica subjacente aos diferentes discursos presentes naquele texto e no contexto. Essa particularidade tornou possível a compreensão, de forma aprofundada, de uma série de eventos mediados pela linguagem, que passou a ser considerada um momento da prática social, algo que produz ações ou efeitos sobre a realidade social.

Esta acepção de linguagem, incorporada pela abordagem sócio-construcionista, desafia a concepção realista/objetivista das organizações e a lógica que ela legitima. Essa apropriação contribuiu para que as organizações fossem concebidas como construções sociais mediadas por discursos e formas culturais que possuem status ontológico diferente da concepção realista de organização. Isso revela, portanto, a presença de concepção antirrealista na teoria das organizações. Nessa visão, a busca por regularidades e generalizações científicas universais tem sido combatida e negada em favor da adoção de concepções ontológicas mais relativistas e politizadas (REED, 2005). Para esse autor, as pesquisas orientadas pelos pressupostos inerentes a esse quadro de referência priorizam as formações e práticas discursivas como elementos constitutivos da realidade social e organizacional linguisticamente mediada. Assim, as formações discursivas e as práticas discursivas estarão necessariamente sujeitas a variações históricas e estruturais próprias de contextos temporais e espaciais em que elas emergem, desenvolvem e são reproduzidas.

Ao destacarem a centralidade da linguagem na produção do conhecimento e na construção da realidade, os precursores do construcionismo social passaram a adotar uma concepção filosófica "anti-fundacionalista" e "anti-objetivista" do conhecimento, que trouxe contribuições relevantes para os estudos em Administração (HOSKING, 2011). Para a autora, reconhecer a linguagem como um momento da prática social significa admitir que a construção da realidade organizacional e do conhecimento sobre ela pode ser realizada a partir das práticas discursivas. Ao mesmo tempo, reconhecer a centralidade da linguagem na produção do conhecimento requer a compreensão das interfaces entre os seus aspectos performáticos e as condições de sua produção em dado contexto sócio-interacional (SPINK e FREZZA, 2004), isto é, diferentes contextos e relações sociais geram sentidos e ações diferentes devido ao caráter histórico e cultural da produção destes sentidos. Assim sendo, os pesquisadores devem estar atento às especificidades do lugar em que as realidades relacionais são construídas, centrando suas atenções sobre o modo como as pessoas constroem e organizam a realidade, incluindo também a sua visão de mundo compartilhada, as práticas sociais e discursivas que perpassam as suas estratégias de ação (GERGEN e THATCHENKERY, 2004; LAINE e VAARA, 2007).

Ao refletir sobre a abordagem construcionista, Sousa Filho (2000) propõe a revisão dos seus pressupostos ontológicos em direção a uma visão crítica. Esse autor argumenta que os adeptos dessa vertente deveriam adotar uma perspectiva mais crítica e reflexiva da realidade, que lhes permita a síntese de concepções, descobertas e conclusões sobre pessoas, cultura e sociedade produzidas no âmbito de diferentes disciplinas. Para tanto, Sousa Filho (2000) propõe diversos questionamentos, tais como: qual seria a concepção construcionista da realidade social? O que deve ser entendido por uma teoria construcionista crítica? Em suas respostas a essas questões, o autor fundamenta-se nos postulados da abordagem construcionista, admitindo que a realidade social, em toda a sua diversidade e em todos os seus aspectos, pode ser abordada como produto da ação dos próprios seres humanos nos seus espaços de viver e nas diferenças de culturas e histórias, incluindo as dimensões imaginárias, simbólicas e subjetivas.

Para Sousa Filho (2000), a perspectiva construcionista crítica se constitui em um modo de pensar filosófico-científico próprio que permite a compreensão da relevância das organizações sociais complexas para a constituição da realidade e da existência humana. Essa concepção possibilita a produção do conhecimento em diferentes áreas do saber, envolvendo análises críticas acerca dos modos de pensar e agir, dos padrões culturais incorporados, dos modos de produção econômicos, dos sistemas políticos, das relações de poder, dos regimes moral e de verdade etc. Para tanto, na visão do autor, os pesquisadores deveriam construir forte engajamento político no sentido de produzir conhecimentos compromissados com a defesa da liberdade, da emancipação política e material das pessoas e da construção de espaços em que a participação e a autonomia possam ser vivenciadas de modo autêntico pela coletividade. Em síntese, defende que todo o conhecimento deve contribuir para desenvolvimento de uma crítica-reflexiva que provoque a transformação da realidade e a emancipação humana. 
Na concepção de Sousa e Filho (2000), o construcionismo crítico postula que toda e qualquer realidade humano-social não teria forma e lugar sem o concurso da ação humana, sendo que a apreensão e análise dessa construção visa compreender a distinção entre a realidade e o real. A realidade diz respeito à dimensão vivida, experienciada ou até mesmo idealizada. Ela envolve as práticas cotidianas e rotineiras e aquelas que são capazes de transformar as organizações, instituições e relações sociais presentes num dado universo. $O$ real, por sua vez, deve ser entendido como o lastro sobre o qual a realidade se estrutura. Trata-se da dimensão que, ultrapassando a realidade imediata, abriga outras dimensões e possibilidades de realidade, configurando-se como algo ilimitado. Entre real e realidade, apresenta-se uma distinção importante: enquanto o real é o domínio das possibilidades e alternativas, a realidade é uma forma do real que não o esgota; enquanto o real é matéria e potência, a realidade é forma e ato. O real abarca a realidade, mas a extrapola, enquanto, por sua vez, a realidade tenta abarcar o real, mas ocultando-o (SOUSA FILHO, 2000).

Há que se considerar, entretanto, que os pressupostos da abordagem sócio-construcionista têm sido alvo de diversas críticas por parte de autores que adotam uma postura realista. Para esses teóricos, a abordagem construcionista seria essencialmente relativista ao admitir o "vale tudo" ("anything goes") epistemológico e o não reconhecimento do "real". No âmbito dos estudos organizacionais, Reed (2005) critica os pesquisadores construcionistas por considerar que eles reduzem a realidade organizacional à linguagem. Para o autor, as organizações deveriam ser apreendidas e analisadas como uma ordem simbólica marcada por uma heterogeneidade discursiva e política, evitando-se a produção de conhecimentos fragmentados sobre a realidade organizacional. A noção de estrutura também desaparece nessa concepção ontológica. Em outras palavras, as estruturas sociais são tratadas como resultados precários de práticas discursivas e de regras que determinam as redes de poder/conhecimento. Por essa razão, torna-se necessário revisar alguns fundamentos do realismo crítico e suas relações com os estudos organizacionais.

\section{REALISMO CRÍTICO}

As ciências humanas e sociais, incluindo as ciências administrativas, experimentaram uma virada ontológica e epistemológica que deu sustentação à emergência da abordagem construcionista. Contudo, observamos que, mesmo diante da predominância do construcionismo nos estudos organizacionais, a referida virada não foi completa. Essa incompletude pode ser explicada pelo fato de que a produção científica em administração encontra-se marcada por fundamentos vinculados a diferentes concepções ontológicas e epistemológicas que constituem a matriz do pensamento administrativo (FARIA, 2012). Essa particularidade deu origem a debates filosóficos cuja principal característica tem sido a ambiguidade e a diversidade de argumentos e pontos de vistas (FLEETWOOD, 2005). Para Faria (2012), essas especificidades, além de dificultar a localização da gênese das diferentes reivindicações ontológicas, obscurece os erros e os equívocos conceituais cometidos por pesquisadores adeptos da orientação construcionista (FLEETWOOD, 2005).

Para mitigar os erros e reflexos decorrentes dessa ambiguidade, Fleetwood (2005) defende a adoção dos postulados do realismo crítico. Ao compartilhar desse ponto de vista, Reed (2005) defende a aplicação do realismo crítico nas ciências sociais, e, em particular nos estudos organizacionais, por considerar que essa abordagem oferece fundamentos mais apropriados e consistentes do que aqueles disponibilizados pela abordagem construcionista. Essa defesa do realismo crítico parece estar atrelada àquilo que Fleck (1979) denominou de estilo de pensamento compartilhado por um dado coletivo de pensamento, ou seja, ao modo de pensar e de agir de um grupo de pesquisadores vinculados a determinada área do conhecimento. Nesse coletivo de pensamento, algumas práticas, concepções, tradições e normas compartilhadas, ao serem tomadas como verdade, passam a determinar o estilo de pensamento que marca a produção do conhecimento. Assim, as referidas abordagens trazem as marcas de estilos de pensamentos singulares que deram origem a modos diferentes de conceber e praticar a pesquisa em Administração. Portanto, seria razoável admitir que as proposições ontológicas moldam a consciência dos pesquisadores e que, por conseguinte, nenhuma teoria emerge em um "vácuo" ontológico.

Nesse sentido, a produção científica implica também em uma reflexão crítica da visão de mundo e de ciência veiculadas pelas proposições teóricas que procuram explicar a realidade. Ao questionar posições historicamente assumidas pela filosofia da ciência, Bhaskar (2000) sintetizou três posturas ontológicas: o empirismo clássico, o idealismo transcendental e o realismo transcendental, do qual ele é signatário. Na primeira concepção, os objetos do conhecimento são considerados como eventos 
atomísticos, sendo a ciência concebida como um "tipo de resposta automática ou comportamental a estímulos de fatos dados e suas conjunções" (BHASKAR, 2000, p. 10). No segundo entendimento, os objetos do conhecimento científico são tomados como modelos ou tipos ideais de ordem natural. Para o autor, os "objetos são construtos artificiais, e embora eles possam ser independentes de homens em particular, não são independentes dos homens ou da ação humana em geral" (BHASKAR, 2000, p. 10). Nessa ótica, o conhecimento é pensado em termos da estrutura, sendo que o mundo é considerado produto da mente humana. O idealismo transcendental não nega a existência de realidade independente da mente humana, mas aponta as dificuldades de acessá-la. A terceira concepção, qualificada pelo autor como realismo transcendental, toma os objetos do conhecimento como estruturas e mecanismos que geram um fenômeno. Sob essa ótica, o conhecimento, enquanto atividade social da ciência, não tem como objeto um fenômeno (empirismo) ou construtos humanos influenciados pelo fenômeno (idealismo), "mas estruturas reais, as quais resistem e operam independentemente do nosso conhecimento, de nossa experiência e das condições que nos permitem ter acesso a elas" (BHASKAR, 2000, p. 10).

Para desenvolver seu pensamento realista, Bhaskar partiu do pressuposto de que a sociedade seria "um conjunto articulado de estruturas gerativas relativamente independentes e duradouras, (ou seja), como uma totalidade complexa sujeita à mudança tanto em seus componentes, quanto em suas inter-relações" (BHASKAR, 2000, p. 11). O autor também reconhece que esse conjunto de estruturas, práticas e convenções pode ser reproduzido e transformado pelas pessoas. Em suas palavras, "a reprodução e/ou transformação da sociedade é uma realização competente de sujeitos ativos, e não uma consequência mecânica de condições antecedentes" (BHASKAR, 2000, p. 12). Além disso, o autor também aponta que as estruturas sociais são ontologicamente diferentes das estruturas naturais, ou seja: i) não existem independentemente das atividades que governam; ii) não existem independentemente das concepções dos agentes acerca do que estejam realizando em sua atividade; iii) podem ser apenas relativamente duradouras, de modo que as tendências sobre as quais se baseiam podem não ser universais no sentido da invariância espaço-temporal. Essas diferenças nos induzem a refletir que a compreensão das estruturas sociais não deve ser submetida ao monismo metodológico e nem a testes de hipóteses. Ao contrário, "os critérios para o desenvolvimento racional e substituição das teorias na ciência social devem ser explanatórios e não-preditivos" (BHASKAR, 2001, p. 18).

As considerações de Bhaskar (2000) foram fundamentais, segundo Vandenberghe (2013) e Reed (2005), para a o desenvolvimento de um estilo de pensamento reflexivo que deu origem a um conjunto de reflexões ontológicas em ciências sociais. Para Reed (2005), o realismo crítico pode ser visto como uma abordagem filosófica que enfatiza a relevância das estruturas ou dos mecanismos gerativos na constituição da realidade, evidenciando o papel ativo dos sujeitos nesse processo. Ao mesmo tempo, do ponto de vista epistemológico, Bhaskar (2000) construiu um estilo de pensamento realista que concebe o conhecimento como produto social que pode ser constituído a partir de saberes ou produções sociais preexistentes (epistemologia); e que defende o pressuposto de que a ação dos objetos do conhecimento ocorre independentemente da atividade do pesquisador. Para desenvolver essa concepção, o autor britânico reconheceu a existência de duas dimensões que marcam a produção do conhecimento: a dimensão transitiva, em que o conhecimento prévio é tomado como referência para gerar um novo conhecimento; e a dimensão intransitiva, em que o objeto do conhecimento pode ser visto como a estrutura real ou mecanismo existente que age independentemente dos pesquisadores e das condições que lhes permitem acesso ao objeto. Para o autor, nessa segunda dimensão, encontram-se objetos intransitivos que são reais (as estruturas, os mecanismos, os processos, os eventos, entre outras possibilidades) que existem independentes das atividades realizadas pelos pesquisadores. Assim sendo, ao admitirmos a existência dos objetos intransitivos, podemos pensar o mundo sem a ciência. Contudo, não seríamos capazes de conceber a ciência sem os objetos transitivos, pois eles são considerados elementos constitutivos do saber prévio que servem de referência para gerar um novo conhecimento, cuja existência depende da ação dos pesquisadores, que podem modificá-lo, reconstruí-lo e transformá-lo ao longo do tempo.

As concepções inerentes ao realismo crítico têm sido apropriadas por diversos pesquisadores da área de administração (FLEETWOOD, 2005). A noção de que uma entidade possa existir independentemente de nosso conhecimento sobre ela é considerada pelo autor como sendo o argumento central da referida perspectiva. Admitir essa concepção ontológica significa reconhecer a possibilidade da sua existência sem que um pesquisador a estude, observe e conheça. Para o autor, o realismo crítico rejeita a neutralidade teórico-metodológica em termos de observação, descrição, interpretação, teorização, explicação etc. Em outras palavras, sob essa ótica ontológica, o acesso à realidade e à construção do conhecimento seriam sempre mediados por algum recurso teórico-metodológico e por conhecimentos preexistentes que servem de referência para interpretar, atribuir sentido, compreender a realidade e imprimir os devidos cursos de ação. Assim, as entidades são conceitualmente mediadas (FLEETWOOD, 2005). 
Para Pimentel e Brito (2011), a existência dessa mediação contribui para o reconhecimento da relevância da concepção ontológica realista para a geração de novos e qualificados conhecimentos em administração. Fundamentados em Bhaskar, esses autores reiteram que a aplicação dos pressupostos ontológicos do realismo crítico possibilita a descrição densa das organizações e do mundo tomado, para efeitos de análises, como sendo estruturado, diferenciado e, principalmente, mutável a partir da ação de agentes ou sujeitos conscientes e reflexivos. O reconhecimento desse postulado, inerente ao realismo transcendental crítico, pode ser visto como o elemento indutor de uma postura crítico-reflexiva que rejeita a afiliação do analista às orientações positivista e empirista.

Arienti (2010) explica que Bhaskar reconhece a existência de três domínios ou dimensões do conhecimento: o real (real), o factual (actual) e o empírico (empirical). Para o autor, o realismo transcendente proposto por Bhaskar defende que a ciência pode ser estratificada e hierarquizada em diferentes domínios, assim como a realidade. No empírico, têm-se as manifestações de um dado fenômeno que podem ser observadas. No domínio do factual, encontram-se os eventos ou a ocorrência de transformações sucessivas na realidade. Por fim, em um nível mais profundo de realidade, tem-se o real, que nos remete às propriedades internas e intrínsecas de cada entidade responsável por desencadear as manifestações de um fenômeno nos diferentes domínios. Nas palavras de Arienti:

A separação entre o real e o empírico implica que as causas estão no domínio real. O domínio factual seria reunião de várias causas, sua combinação para a expressão em eventos e fenômenos. A percepção dos fenômenos está no domínio empírico. No domínio real estão as estruturas, mecanismos e poderes que podem ser acionados ou não e estão presentes na realidade independente de sua atualização em eventos e fenômenos e percepção no domínio empírico (ARIENTI, 2010, p. 4-6).

Assim, segundo Arienti (2010), a proposição inovadora do realismo bhaskariano não se restringe ao caráter transcendente das estruturas no domínio real. Na verdade, o vigor dessa proposição se estende, também, ao tratamento da conjunção das forças estruturais no domínio factual, sendo que o empírico também pode ser compreendido em perspectiva de sistema aberto.

Ao discutir os pressupostos da ontologia realista crítica, Fleetwood (2005) apresenta uma sistematização relevante para compreender a organização como parte do domínio real. Para o autor, os realistas críticos consideram como sendo real a entidade que possui eficácia causal; aquela que produz efeitos sobre os comportamentos. Por sua vez, as entidades sociais se particularizam por apresentar as seguintes propriedades: i) não contêm materialidade; ii) dependem da atividade humana para sua existência; iii) existem independentemente de nossa identificação; iv) podem ou não ser conceitualmente mediadas; v) possuem extra-discursividade e não podem ser confundidas com entidades ideais, tais como teorias ou explicações. A partir dessas considerações, Fleetwood (2005) argumenta que existem diferentes tipos de realidade. De acordo com o autor, o real material refere-se a entidades materiais como oceanos, clima, Terra, Lua e assim por diante, que podem existir independentemente do que indivíduos ou comunidades fazem, dizem ou pensam. Essas entidades podem ser afetadas pela ação humana em alguns casos, e sua existência pode ser independente do nosso conhecimento. No caso daquelas que conhecemos, nós as tomamos como entidades materiais conceitualmente mediadas, sendo que o ato de mediação não altera seu estado material. Já o real ideal envolve as entidades conceituais que produzem efeitos, tais como os discursos hegemônicos, a linguagem, os signos, os símbolos, as ideias, as crenças, os sentidos, as compreensões, as explicações, os conceitos, as teorias e congêneres. Essas entidades são consideradas reais porque possuem eficácia causal. Tem-se, ainda, o real artefatual, constituído por entidades como tecnologias, máquinas, computadores, que podem sintetizar o real físico, real ideal e real social em uma mesma perspectiva. Por fim, o real social refere-se às práticas, ações em si mesmas, a exemplo das práticas de gestão, da atuação em mercado ou a participação em estruturas sociais ou organizacionais. Os realistas críticos usam o termo "estruturas sociais" para se referir a configurações de mecanismos causais, regras, recursos, relações, poderes, posições e práticas (FLEETWOOD, 2005).

Pelas reflexões e argumentações de Bhaskar (2000), Fleetwood (2005), Kemp (2005), Reed (2005), Arienti (2010) e Pimentel e Brito (2011), podemos observar as especificidades da ontologia realista crítica. Esse último autor aponta também três pressupostos ontológicos centrais que podem complementar a nossa visão do realismo crítico enquanto filosofia da ciência: primeiro, os fenômenos para os quais a pesquisa e a explicação científica encontram-se direcionados são as estruturas e os mecanismos que produzem eventos empíricos, ao invés de, como no positivismo, gerarem os eventos empíricos ou regularidades empíricas em si mesmas. O realismo crítico propõe uma concepção ontológica que reconhece diferentes domínios 
de realidade, considerando tanto as estruturas ou mecanismos mais profundos que definem eventos, como as regularidades no domínio mais superficial da realidade. Segundo, Reed (2005) afirma que essas estruturas não são diretamente acessíveis à experiência e devem ser teoricamente construídas e formuladas por meio da abstração conceitual e retrodução. Essa particularidade, em especial, separa o realismo crítico do realismo empírico e do determinismo material característico das filosofias empiristas e positivistas da ciência. Terceiro, assim como as expliçções de estruturas ou mecanismos que geram eventos e resultados contingenciais, as teorias científicas oferecem descrições provisórias, produzindo argumentações que estarão sempre abertas a revisão e reformulação. Assim, o realismo crítico insiste que é possível, e até mesmo necessário, avaliar teorias científicas e explicações concorrentes em relação a seu poder explicativo de descrições e considerações que elas fornecem para a compreensão das estruturas e mecanismos geradores de eventos e padrões observáveis e resultados contingenciais (REED, 2005).

Para Reed (2005), os pressupostos ontológicos-realistas produziram diversas repercussões teóricas e metodológicas. Primeiro, o realismo crítico defende uma concepção e explicação de causalidade fundamentalmente diferente daquela preconizada pelo positivismo. A causalidade deve ser vista como a relação entre eventos discretos, não podendo, portanto, ser reduzida à aplicação e às generalizações estatísticas decorrentes de métodos quantitativos de pesquisa. Ao contrário, ela deve produzir descrições e interpretações sobre a capacidade dos mecanismos ou estruturas em gerar certas tendências ou regularidades que podem ou não ser contingencialmente observadas em eventos ou resultados empíricos. Segundo, essa postura exige a realização de pesquisas orientadas pela lógica retrodutiva, quase difere da concepção dedutiva inerente ao positivismo e da proposição abdutiva típica da abordagem construcionista e de perspectivas pós-modernistas. A retrodução, enquanto modo de inferência, permite a produção de conhecimentos sobre as estruturas ou mecanismos produtores de regularidades ou tendências, que podem ser descobertas e explicadas, a partir da aplicação de formulações teóricas e procedimentos de pesquisa. Em terceiro lugar, reconhecer a relevância da teoria não significa admitir que a produção do conhecimento possa ser reduzida à simples análise de práticas discursivas e esquemas interpretativos empregados pelos agentes na compreensão da realidade. $O$ realismo crítico parte de concepção ontológica distinta, pois defende o desenvolvimento de pesquisas orientadas pelo modo de inferência retrodutivo e pautadas em aplicação de metodologias de explicação causal que permitam a explicação e a rejeição da predição e desconstrução do comportamento social. O conhecimento científico, sob essa ótica, deve gerar explicações para as estruturas, gerando também padrões ou regularidades de elevada complexidade, frequentemente marcados por ações contraditórias e conflituosas que derivam das estruturas socais e dos mecanismos inerentes a situações sociais e organizacionais inseridas em contextos dinâmicos (REED, 2005). Além dessas particularidades, não podemos desconsiderar as dimensões intransitiva e transitiva do conhecimento e o fato de o realismo crítico defender que a epistemologia seja orientada pela ontologia, e não o contrário. Esse deslocamento, proporcionado pelo realismo crítico, traz implicações relevantes para a reformulação de pesquisas em sistemas sociais e em organizações.

Ao concluir suas reflexões, Reed (2005) afirma que o realismo crítico rejeita a ideia de que as nossas compreensões e interpretações construídas socialmente sejam exaustivas da realidade. Para o autor, as descrições, explicações e avaliações teóricas estão ancoradas em processos de geração e disseminação do conhecimento que se encontram situadas no tempo e no espaço ou nas configurações sócio-históricas. Em outros termos, as nossas explicações e avaliações teóricas serão sempre provisórias, falíveis, contestáveis e passíveis de revisão. Contudo, a falibilidade e provisoriedade do conhecimento não legitima a redução da realidade à linguagem ou às práticas discursivas. Sendo assim, o realismo crítico nos fornece um conjunto de pressupostos que, se forem bem compreendidos e aplicados, podem contribuir para a reconstrução da teoria social e organizacional. Portanto, o reconhecimento dos pressupostos acima discutidos pode contribuir para a redefinição da natureza e do potencial explicativo na análise social e organizacional, ampliando a nossa compreensão e participação em formas sócio-organizacionais emergentes (REED, 2005).

Por fim, Fleetwood (2005) destaca que a ontologia realista nos permite compreender a dinâmica entre agência e estrutura sob uma ótica transformadora, que reconhece a realização competente de sujeitos ativos na reprodução e transformação da vida social e organizacional. Para o autor, a compreensão dessa dinâmica transformadora sob a perspectiva ontológica realista crítica tem contribuído para o avanço da teoria social e organizacional. Essas contribuições estariam atreladas à diferenciação dos diferentes modos de realidade, à admissão da existência de uma dimensão extradiscursiva na vida social e organizacional, e ao reconhecimento da relevância das entidades (agência e estrutura) mediadas conceitualmente, que podem ser analisadas de forma relacional e dinâmica. 


\section{REALISMO CRÍTICO E CONSTRUCIONISMO SOCIAL: SIMILARIDADES E COMPLEMENTARIDADE}

Nesta seção, temos como objetivo apontar as aproximações entre alguns fundamentos do realismo crítico e do construcionismo social. Destacamos que temos consciência das reflexões de autores que reforçam a tese da incomensurabilidade entre estes quadros de referência. Contudo, optamos por sistematizar argumentos de diversos autores que destacaram similaridades e complementaridades entre as referidas concepções. Em outros termos, reconhecemos a relevância do debate em torno da incomensurabilidade, mas adotamos o posicionamento de não acirrá-lo, por considerarmos que, neste momento, esta escolha seria pouco produtiva.

Fleetwood (2005) argumenta que, apesar de todas as críticas, os defensores mais moderados do construcionismo social e do realismo crítico começaram a reconhecer alguns pontos de interseção entre essas concepções filosóficas. A partir desse reconhecimento, buscamos agora verificar a existência de uma base conceitual a partir da qual seria possível abrir um diálogo efetivo entre realismo crítico e construcionismo social. Para tanto, exploramos algumas evidências que possibilitam responder a este desafio, limitando-nos a lançar algumas sementes para a comensurabilidade entre as abordagens. Temos consciência de que essa empreitada exige novas investidas intelectuais que poderão aprofundar o debate em torno desta questão.

Por um lado, podem ser observadas evidências iniciais desse diálogo em algumas posições moderadas do construcionismo social. Grand, Rüegg-Stürm e Von Arx (2010) reiteram que o construcionismo foca na construção da realidade e do conhecimento como resultado de certos processos. Essa realidade social pode, segundo os autores, ser apreendida de forma objetiva e subjetiva. A realidade objetiva, embora resultante de construção social, aparece para o indivíduo como dada, enquanto a realidade subjetiva refere-se à contínua construção ou produção de sentidos cuja origem está vinculada as interações cotidianas. Esses autores afirmam, ainda, que as epistemologias construcionistas não discutem apenas o mundo "como ele é", mas refletem sobre a contingência da realidade e do conhecimento, gerando interesses em identificar mundos possíveis "como eles poderiam ser", ou mesmo produzir questões sobre como poderíamos "mudar o mundo como ele é" (GRAND, RÜEGGSTÜRM e VON ARX, 2010).

Por outro lado, também podem ser observadas evidências iniciais desse diálogo em algumas posições moderadas do realismo crítico. Autores como Klein (2004) e Hunt (2005) apontam que o realismo crítico assume uma posição que reconhece a realidade como estando presente tanto no discurso como nas entidades. Nesse sentido, embora rejeite a generalização e a redução de tudo ao nível do discurso, verifica-se que o realismo crítico não assume, como o faz o positivismo e outros tipos de realismos, uma posição e um quadro de estabilidade, sem espaço para a ação humana e social. Logo, tem-se a raiz da concepção crítica do realismo crítico, que se vincula exatamente a esse movimento e a esse exercício crítico, transformativo e, até mesmo, emancipatório da realidade social.

A síntese dos argumentos que apresentamos acima expõe uma primeira possibilidade efetiva de diálogo entre o construcionismo social e o realismo crítico. Em suas versões moderadas, ambos podem lidar com aspectos vinculados à realidade social e à abertura para a emancipação e transformação social. A partir disso, as duas abordagens podem assumir uma posição ontológica, de certo modo, comum, ou pelo menos, complementar.

Uma segunda possibilidade efetiva de diálogo pode ser visualizada a partir do debate clássico entre agência e estrutura. Em uma visão polarizada e radical, o construcionismo estaria vinculado à agência humana, e o realismo estaria ligado à estrutura. Todavia, as versões moderadas do construcionismo social e do realismo crítico tendem a buscar a superação da dicotomia entre agência e estrutura, visualizando-as de forma muito mais integrada, relacional e dinâmica. Nesse caso específico, reforçam-se as contribuições ontológicas do realismo crítico e também as versões do construcionismo social, as quais corroboram para o delineamento de uma postura teórico-metodológica que permite a apreensão da dialogia agência-estrutura. Uma das alternativas seria a adoção de uma dupla orientação fundamentada, de um lado, pela postura ontológica realista crítica, que defende a existência da realidade e que reconhece os três domínios do conhecimento: o real, o factual e o empírico. Do outro lado, a fundamentação se dá pela epistemologia sócio-construcionista que: i) toma a pesquisa científica ou o modo pelo qual produzimos conhecimento como uma prática social crítica e reflexiva; ii) rejeita o monismo metodológico proposto por Karl Popper; iii) defende o alinhamento entre método e postura epistemológica; nega a separação entre sujeito e objeto de pesquisa; iv) responsabiliza o pesquisador pela descrição e exploração do contexto sócio-histórico da pesquisa; v) reconhece a processualidade da construção do conhecimento e da transformação social, entre outras particularidades (SPINK e MENEGON, 2004). 
Uma terceira possibilidade de diálogo surge com a contribuição de Al-Amoudi e Willmott (2011). Inicialmente, os autores demonstram que tanto o realismo como o construcionismo emergiram como categorias amplas e distintas para a caracterização de formas de análise e de afiliações teóricas, destacando a ausência de conversações entre elas. Esse foi um dos argumentos utilizados pelos autores para justificar a sistematização de alguns pontos de convergência e para defender o estabelecimento de diálogos entre as referidas concepções. Para Al-Amoudi e Willmott (2011), o relativismo epistemológico expressa a ideia de como nossas categorias, quadros de pensamento, modos de análise, modos de ver as coisas, hábitos de pensamento, disposições cotidianas, preocupações, interesses, valores e assim por diante, são afetados por nossas trajetórias de vida e situações socioculturais. Estas categorias nos servem de referência para a interpretação, compreensão e geração de novos conhecimentos. No realismo crítico, essa possibilidade foi denominada de dimensão transitiva do conhecimento. Esse ponto de contato foi ressaltado pelos autores, que argumentam que essa concepção, própria da abordagem construcionista, pode ser adotada por realistas críticos. Dessa forma, eles estariam mantendo a concepção ontológica que defende a dimensão intransitiva do conhecimento e reforçando o posicionamento epistemológico realista ao conceber que o desenvolvimento racional (reformulação, modificação, transformação) e substituição de teorias sociais devem ser "explanatórios e não-preditivos" (BHASKAR, 2001, p. 18). Portanto, a dimensão transitiva do conhecimento permite que o diálogo se estabeleça entre as referidas abordagens. Essa possibilidade ficaria mais evidente na medida em que os pesquisadores afiliados a essas abordagens fossem capazes de identificar os pontos de convergência, a exemplo do reconhecimento da falibilidade do conhecimento (sujeito a erros) reconhecida tanto por realistas críticos como por construcionistas. Como nos lembram Al-Amoudi e Willmott (2011), reconhecer a possibilidade de erros não significa admitir que todo conhecimento seja potencialmente errado, mas significa reconhecer seu caráter transitório e histórico, a sua localização no tempo e espaço ocupado por pesquisadores que também se posicionam e fazem escolhas ontológicas e epistemológicas.

Adicionalmente, o diálogo entre o realismo crítico e o construcionismo social poderá ser frutífero à medida que os pesquisadores diferenciem a postura ontológica da epistemológica. Essa diferenciação, segundo Al-Amoudi e Willmott (2011), possibilitaria o compartilhamento de referências necessárias à realização de escolhas mais apropriadas entre teorias alternativas. Assim, a afiliação aos fundamentos da epistemologia construcionista permitiria aos realistas críticos fazerem suas escolhas considerando que os mecanismos gerativos do conhecimento são mediados por processos cultural e historicamente mutáveis. Reiteramos que os critérios de escolha de uma explicação sobre a outra será, pelo menos em parte, dependente do estilo de pensamento partilhado pelos membros da comunidade histórico-cultural em que as versões explicativas foram produzidas. Esse processo de mediação também está presente na dimensão transitiva do conhecimento, fazendo parte de uma concepção epistemológica e a sua produção será sempre mediada por fundamentos teóricos e metodológicos disponíveis (FLEETWOOD, 2005). Para Fleetwood (2005), não existe observação, descrição, interpretação, teorização e explicação neutras teoricamente. Consequentemente, o acesso ao conhecimento passa necessariamente por um processo de mediação. Sempre que buscamos compreender o real social recorremos a esse processo, sendo que o sentido atribuído ao real será sempre mediado pelos de recursos conceituais preexistentes que são utilizados para interpretar e compreender as especificidades daquela entidade (FLEETWOOD, 2005; AL-AMOUDI e WILLMOTT, 2011).

Prosseguindo suas reflexões sobre a possibilidade de conversações entre as referidas abordagens, Al-Amoudi e Willmott (2011) sugerem que seria mais coerente tomar o realismo crítico como uma concepção ontológica apropriada para compreender como o real é discursivamente construído, evitando-se considerá-la um modo de acesso ao real. Para os autores, o grande desafio a ser enfrentado pela abordagem realista crítica seria o reconhecimento do caráter contingente e discursivo da dimensão intransitiva da ciência social; isto é, o referido diálogo requer que o realismo crítico se afirme como um discurso, incluindo suas lógicas de referência. Nesse sentido, o realismo crítico, orientado por uma epistemologia construcionista, poderia ser concebido como um discurso cujo apelo está relacionado à sua relevância para a interpretação e explicação das contingências histórico-culturais hegemônicas. Essa possibilidade também poderia contribuir para o entendimento, não só da falibilidade do conhecimento, mas também para a compreensão de que sua produção e credibilidade estão imbricadas em processos históricos, políticos e sociais (AL-AMOUDI e WILLMOTT, 2011).

Há que se considerar, ainda, uma quarta possibilidade de diálogo entre o construcionismo social e o realismo crítico. ElderVaas (2012) inicia sua argumentação retomando a concepção original do construcionismo social, frequentemente ligado a uma ontologia antirrealista do mundo social. Ao privilegiarem a linguagem, o discurso, e/ou a cultura como construções sócio-históricas, os adeptos da abordagem construcionistas e posicionaram de modo oposto, criticando a concepção ontológica do 
realismo, especialmente aquelas formuladas pelos adeptos do realismo empírico ou clássico. Na visão do autor, essa abordagem privilegiou a construção social e sua dimensão subjetiva, colocando em segundo plano o seu potencial crítico e transformador. Partindo dessa argumentação, Elder-Vaas (2012) afirma que este potencial poderia ser retomado a partir do momento em que os adeptos do construcionismo incorporassem alguns elementos filosóficos do realismo crítico, especialmente no que diz respeito ao caráter das estruturas e mecanismos de transformação da realidade. Nesta ótica, por exemplo, a cultura, a linguagem e as práticas discursivas poderiam ser abordadas, por um lado, como produtos sócio-históricos decorrentes da interação entre múltiplos poderes causais e, por outro, como produtora de efeitos e forças causais e, portanto, constituintes e constitutivas do real. $\mathrm{O}$ autor propõe o desenvolvimento de uma ontologia social da linguagem, do discurso e da cultura que ofereça aos pesquisadores os fundamentos para a compreensão das entidades, poderes e mecanismos em funcionamento. Essa possibilidade poderia contribuir para a diferenciação e para a reformulação de algumas concepções construcionistas, fortalecendo o seu compromisso com a transformação da sociedade e a emancipação dos sujeitos, bem como possibilitaria uma compreensão mais qualificada dos efeitos da estrutura e da linguagem na construção do conhecimento e do real.

Ao concluir as suas reflexões, Elder-Vaas (2012) sugere o aprofundamento da conversação filosófica entre as abordagens e defende que os adeptos do construcionismo social incorporem em suas pesquisas uma ontologia social realista crítica, de modo a oferecer uma abordagem coerente para o desenvolvimento de teoria social. Para tanto, o autor afirma que será necessário compreender que a construção social retoma a dimensão objetiva da realidade e entende que o mundo material faz parte dela. Esta postura aproxima-se da noção de um agenciamento recíproco entre coisas e humanos proposta por Ludwik Fleck (1979) e a relocaliza em um cenário mais adequado para as ciências sociais e para a teoria das organizações. Dessa forma, a ontologia híbrida proposta pelo autor resgata concepções de um realismo redesenhado a partir de uma concepção ontológica crítica e incorpora matizes construcionistas. Essa proposta prevê uma espécie de duplo agenciamento: o realista crítico, que reconhece as coisas do mundo, e o construcionista, que reconhece o papel dos agentes. Assim, esta ontologia hibrida estabelece conexões entre as entidades sociais e os agentes, permitindo que os realistas aceitem a subjetividade como sendo parte do real sem, contudo, abandonar a realidade do sujeito e suas concepções acerca da existência das estruturas (ELDER-VAAS, 2012).

A partir das questões discutidas acima, acreditamos que a junção entre construcionismo social e realismo crítico, desde que respeitados os limites de cada abordagem, pode contribuir para a consolidação de uma abordagem construcionista-realista ou realista-construcionista. Nessa perspectiva, teríamos uma concepção cujos pressupostos poderiam produzir interpretações e explicações fundamentadas numa ontologia híbrida (dimensão intransitiva) e em uma postura epistemológica e metodológica alinhada com a natureza do problema e com os objetivos do conhecimento (dimensão transitiva), abrindo possibilidades para a construção de pesquisas referenciadas nesse posicionamento ontológico e epistemológico, contribuindo de forma importante para a administração e para os estudos organizacionais.

\section{CONSIDERAÇÕES FINAIS}

Neste artigo, procuramos tecer reflexões de natureza ontológica e epistemológica sobre a pesquisa em Administração. Mais precisamente, efetuamos algumas considerações que estabelecem os fundamentos de um possível diálogo entre realismo crítico e construcionismo social, formando, assim, um quadro de referência para o desenvolvimento dos estudos organizacionais. Para tanto, foram retomadas as principais formulações e elaborações disponíveis sobre cada uma dessas concepções, de modo a situar as suas especificidades e respectivos pressupostos ontológicos e epistemológicos centrais. De forma complementar, foram apontadas algumas contribuições dessa aproximação para os estudos organizacionais, ressaltando seu potencial filosófico para a construção de pesquisas de natureza multirreferenciais em termos ontológicos e epistemológicos.

O conjunto de evidências apresentadas no artigo revela diferentes possibilidades de diálogo entre o construcionismo social e o realismo crítico. Acreditamos que esse diálogo pode produzir efeitos significativos e contribuições relevantes para a investigação social e organizacional. Ele pode promover a sensibilização de estudiosos e pesquisadores no sentido de reconstruírem suas agendas de produção de saberes organizacionais, especialmente no que tange à construção de saberes em termos ontológicos, epistemológicos e teórico-metodológicos. Do ponto de vista teórico, o referido diálogo poderá contribuir para potencializar estudos críticos em organizações, incorporando categorias de análise como prática social, discurso, hegemonia, 
poder, ideologia, vigilância, transformação da realidade, emancipação humana, dentre outras inúmeras possibilidades. Do ponto de vista metodológico, também poderá estimular a triangulação de diferentes métodos e técnicas de pesquisa de natureza qualitativa, a exemplo da etnometodologia, da etnografia, da pesquisa-ação, da pesquisa longitudinal e contextualista, dentre outros métodos que se alinhem com ao diálogo aqui proposto.

Em síntese, concluímos que a articulação entre os fundamentos filosóficos do construcionismo social e do realismo crítico pode, no limite, contribuir para a configuração de abordagem híbrida caracterizada por uma orientação ontológica realista crítica e uma postura epistemológica-construcionista. Obviamente, o desenvolvimento dessa abordagem requer outras reflexões, incluindo os aspectos axiológicos que marcam a produção do conhecimento. Para tanto, sugerimos que os pesquisadores tenham cautela, de modo a evitar que axiomas e pressupostos contraditórios e mutuamente exclusivos não sejam tomados como similares e complementares.

Por fim, uma ressalva se faz necessária: neste trabalho, não tivemos a intenção de esgotar esse debate, mas sim de estabelecer um dos pontos de partida possíveis para instigar essa discussão, sobretudo no âmbito dos estudos organizacionais brasileiros. Sendo assim, esperamos que este ensaio forneça pistas iniciais para o debate, abrindo caminho para novas possibilidades para os estudos organizacionais. 


\section{REFERÊNCIAS}

AL-AMOUDI, I.; WILLMOTT, H. Where Constructionism and Critical Realism Converge: Interrogating the Domain of Epistemological Relativism. Organization Studies, v. 32, n. 1, p. 327-46, 2011.

ARIENTI, W. L. Realismo crítico e o ensino de economia: em direção à ontologia. In: ENCONTRO NACIONAL DE ECONOMIA, 38., 2010. Niterói. Anais... ANPEC: Rio de Janeiro, 2010. CD-ROM.

BAERT, P. Towards a pragmatist-inspired philosophy of social science. Acta Sociologica, v. 48, n. 3, p. 191-203, 2005.

BARBOSA, M. A. C. et al. Nem só de debates epistemológicos vive o pesquisador em Administração: alguns apontamentos sobre disputas entre paradigmas e campo científico. Cad. EBAPE.BR, v. 11, n. 4, p. 636-636, 2013.

BERGER, P. L.; LUCKMANN, T. A Construção Social da Realidade: tratado da sociologia do conhecimento. 25. ed. Petrópolis: Vozes, 2005. 274 p.

BHASKAR, R. Uma Teoria Realista da Ciência. Niterói: UFF, 2000.

BRANDÃO, A. R. P. A postura do positivismo com relação às ciências humanas. Theoria - Revista Eletrônica de Filosofia, v. 3, n. 6, p. 80-105, 2011.

BURR, V. An Introduction to Social Constructionism. London: Sage Publications, 1985.

CRESWELL, J. W.; CLARK, V. L. P. Designing and conducting mixed methods research. Thousand Oaks: Sage, 2007. 296 p.

CUNLIFFE, A. L. Orientations to social constructionism: relationally responsive social constructionism and its implications for knowledge and learning. Management Learning, v. 39, n. 2, p. 123-139, 2008

DAMKE, E. J.; WALTER, S. A.; SILVA, E. D. A administração é uma ciência? Reflexões epistemológicas acerca de sua cientificidade. Revista de Ciências da Administração, v. 12, n. 28, p. 127-146, 2010.

ELDER-VASS, D. Towards a Realist Social Constructionism. Sociologia: Problemas e Práticas, v. 20, n. 70, p. 9-24, 2012.

FARIA, J. H. Teoria Crítica em Estudos Organizacionais no Brasil: o estado da arte. Cadernos EBAPE.br, v. 7, n. 3, p. 509-515, set. 2009.

FARIA, J. H. Dimensões da matriz epistemológica em estudos em administração: uma proposição. In: ENCONTRO DA ASSOCIAÇÃO DE PÓS-GRADUAÇÃO E PESQUISA EM ADMINISTRAÇÃO, 36, 2012, Rio de Janeiro. Anais... Rio de Janeiro: ANPAD, 2012. CD-ROM.

FLECK, L. The Genesis and Development of a Scientific Fact. Chicago: Univ. of Chicago, 1979.

FLEETWOOD, S. Ontology in organization and management studies: a critical realist perspective. Organization, v. 12, n. 2, p. 197-222, 2005

FRANCELIN, M. M. Abordagens em epistemologia: Bachelard, Morin e a epistemologia da complexidade. Transinformação, v. 17, n. 2, p. 101-109, mai./ago. 2005

GERGEN, K. J. The Social Constructionist Movement in Modern Psychology. American Psychologist, v. 40, n. 3, p. 266-275, mar. 1985.
GERGEN, K.; THATCHENKERY, J. T. Organization Science as Social Construction: Postmodern Potentials. The Journal of Applied Behavioral Science, v. 40, n. 2, p. 228-249, 2004.

GRAND, S.; RÜEGG-STÜRM, J.; VON ARX, W. Constructivist epistemologies in Strategy as Practice Research. In: GOLSORKHI, D. et al. (Org.). Cambridge Handbook of Strategy as Practice. Cambridge: Cambridge University Press, 2010.

HAMLIN, C. L. Realismo crítico: um programa de pesquisa para as Ciências Sociais. Dados, v. 43, n. 2, 2000.

HOLMWOOD, J. Pragmatism and the prospects of sociological theory. Journal of Classical Sociology, v. 11, n. 1, p. 15-30, 2011.

HUNT, S. For truth and realism in management research. Journal of Management Inquiry, v. 14, n. 2, p. 127-138, 2005.

KEMP, S. Critical Realism and the Limits of Philosophy. European Journal of Social Theory, v. 8, n. 2, p. 171-191, 2005.

KLEIN, H. K. Seeking the new and the critical in critical realism: déjà vu? Information and Organization, v. 14, p. 123-144, 2004.

LAINE, P. M.; VAARA, E. Struggling over subjectivity: a discursive analysis of strategic development in an engineering group. Human Relations, v. 60, n. 1, p. 29-58, 2007.

LECLERCQ-VANDELANNOITTE, A. Organizations as Discursive Constructions: A Foucauldian Approach. Organizations Studies, v. 32, n. 9, p. 1247-1271, 2011.

LINCOLN, Y. S.; LYNHAM, S. A.; GUBA, E. G. Paradigmatic Controversies, Contradictions, and Emerging Confluences: Revisited. In: DENZIN, N. K.; LINCOLN, Y. S. (Orgs.). The Sage Handbook of Qualitative Research. London: Sage Publications, 2011. 97-128 p.

MENEGHETTI, F. K. Pragmatismo e os pragmáticos nos estudos organizacionais. Cad. EBAPE.BR, v. 5, n. 1, p. 1-12, 2007.

PIMENTEL, T. D.; BRITO, M. J. Realismo crítico nos estudos organizacionais: notas introdutórias sobre seus fundamentos filosóficos. In: ENCONTRO DA ASSOCIAÇÃO NACIONAL DE PÓS-GRADUAÇÃO E PESQUISA EM ADMINISTRAÇÃO, 35, 2011, Rio de Janeiro. Anais... Rio de Janeiro: ANPAD, 2011. CD-ROM.

PRASAD, A. The Contest Over Meaning: Hermeneutics as an Interpretive Methodology for Understanding Texts. Organizational Research Methods, v. 5, n. 1, p. 12-33, jan. 2002.

REED, M. Reflections on the 'Realist Turn' in Organization and Management Studies. Journal of Management Studies, v. 42, n. 8, p. 1621-1644, 2005.

ROBERGE, J. What is critical hermeneutics? Thesis Eleven, v. 106, n. 1, p. 5-22, 2011.

SERVA, M. Epistemologia e Ciência da Administração. Cad. EBAPE. BR, v. 11, n. 4, p. 500-502, 2013

SERVA, M.; DIAS, T.; ALPERSTEDT, G. D. Paradigma da Complexidade e Teoria das Organizações: Uma Reflexão Epistemológica. Revista de Administração de Empresas, v. 50, n. 3, p. 276-287, jul./set. 2010. 
SERVA, M.; PINHEIRO, D. M. Epistemologia e Sociologia da Ciência da Administração: uma reflexão inicial sobre os estudos do campo no Brasil. In: ENCONTRO DA ASSOCIAÇÃO NACIONAL DE PÓSGRADUAÇÃO E PESQUISA EM ADMINISTRAÇÃO, 33, 2009, São Paulo. Anais... ANPAD: Rio de Janeiro, 2009. CD-ROM.

SILVINO, A. M. D. Epistemologia Positivista: Qual a sua Influência Hoje? Psicologia: Ciência e Profissão, v. 27, n. 2, p. 276-289, jun. 2007.

SOUSA FILHO, A. Por uma teoria construcionista crítica. Bagoas, v. 1, n. 1, p. 1-34, 2007.

SOUZA, E. M.; SOUZA, S. P.; SILVA, A. R. L. O pós-estruturalismo e os estudos críticos de gestão: da busca pela emancipação à constituição do sujeito. Revista de Administração Contemporânea, v. 17, n. 2, p. 198-217, 2013.
SPINK, M. J.; FREZZA, R. M. Práticas discursivas e produção de sentidos: a perspectiva da Psicologia Social. In: SPINK, M. J. (Org.). Práticas discursivas e produção de sentidos no cotidiano: aproximações teóricas e metodológicas. São Paulo: Cortez, 2004. 13-40; 63-92 p.

VAARA, E. Taking the Linguistic Turn Seriously: Strategy as a Multifaceted Interdiscursive Phenomenon. Advances in Strategic Management, v. 27, n. 1, p. 29-50, 2010.

VANDENBERGHE, F. What's critical about critical realism?: essays in reconstructive social theory. London: Routledge, 2013.

VERGARA, S. C.; CALDAS, M. P. Paradigma Interpretacionista: a Busca da Superação do Objetivismo Funcionalista nos Anos 1980 e 1990. Revista de Administração de Empresas, v. 45, n. 4, p. 66-72, out./dez. 2005.

Alex Fernando Borges

Doutorando em Administração pela Universidade Federal de Lavras/UFLA; Professor assistente da Universidade Federal de Uberlândia. E-mail: alexfborges@gmail.com

\section{Mozar José de Brito}

Doutor em Administração pelo PPGA/USP; Professor do Programa de Pós-Graduação em Administração e do Programa de Pós-Graduação em Administração Pública da Universidade Federal de Lavras; Pesquisador do CNPq e Fapemig. E-mail: mozarjdb@dae.ufla.br

Valéria da Glória Pereira Brito

Doutora em Administração pela Universidade Federal de Minas Gerais/CEPEAD; Professora associada da Universidade Federal de Lavras.

E-mail:vgpbrito@gmail.com

\section{Alessandro Gomes Enoque}

Doutor em Sociologia pela Universidade Federal de Minas Gerais/FAFICH; Professor adjunto da Universidade Federal de Uberlândia. E-mail: alessandroenoque@pontal.ufu.br 